will be extended to the ophthalmic departments of other hospitals and to the provinces. The surgeon who advises the patient is to receive the fee for consultation. The great advantage of this scheme is that it would be less expensive to manage, a more efficient staff would be obtained and a proper supervision would be given to the clinic. It is unfortunate that the British Medical Association scheme and hospital scheme cannot be so modified as to work in conjunction with each other. It is obvious that the majority of ophthalmic surgeons, at any rate in London, would not agree to work under the conditions of the British Medical Association scheme, at rooms or shops set up by an optician at his own expense.

\title{
Elementary Ophthalmic Ethics
}

We understand that a circular letter has been addressed to ophthalmologists by the Secretary of the British Medical Association, calling attention to the fact that, according to information received, "a body of sight-testing opticians is circularising registered medical practitioners who practise as ophthalmic surgeons inviting them to place their names upon ' a Register of ophthalmic surgeons for the use of Approved Societies in cases which, having been examined by a qualified optician upon the register of the Joint Council of Qualified Opticians, were referred for further advice or treatment.' This list is to be compiled by the Sight-testing Opticians' Society upon the recommendation of local sight-testing opticians."

The secretary of the British Medical Association points out that there is " already in existence a list of approved ophthalmic medical practitioners prepared by the British Medical Association, printed and issued by the Ministry of Health. This list is furnished to Approved Societies and other responsible persons on request."

The secretary of the British Medical Association emphasises the fact that any medical practitioner allowing his name to be placed upon such a list, prepared by a lay body for the use of other lay bodies, is liable for grave reflection cast upon his character for a breach of professional ethics. " Such action," he says," cannot but be regarded as an undesirable method of gaining introductions to patients." This is a fact which is patent to all responsible medical practitioners, and needs no further comment from us. 